\title{
EVALUASI PROGRAM PENDIDIKAN KESEHATAN MASYARAKAT MODEL STAKE DI DESA PENGLIPUURAN KUBU BALI
}

\author{
Nyoman Ribek ${ }^{1},{ }^{*}$, Putu Susy N.AI ${ }^{2}$, Made Mertha ${ }^{3}$ \\ 1 Jurusan Keperawatan Politeknik Kesehatan Denpasar \\ 2 Jurusan Keperawatan Politeknik Kesehatan Denpasar \\ ${ }_{3}^{3}$ Jurusan Keperawatan Politeknik Kesehatan Denpasar
}

\section{Abstrak}

Evaluation model programs stake of health education programs to improve community health. Research aims to investigate the implementation of health education programs to improve community health status Penglipuran Bangli regency. This research is descriptive qualitative research in the form of program evaluation with a design evaluation model programs stake, s. Non probability sampling with purposive sampling. with a sample of 12 informants, health education receiver 5 and 70 filler questionnaires. The data collected by in-depth interviews, documentation, observation and angket. Data analyzed with logical, empirical, and consideration of the suitability of the results. The study concluded there Relevance sufficient to describe the consistency of goals, policies, and services, to meet the needs of the community health education, Still efektip level of achievement of targets, and standard operating procedures were implemented in health education programs, is quite efficient in seeing a comparison between the output with input, Impact positively influence the implementation of health education on health behaviors.
\end{abstract}

\section{Keywords:}

Evaluasi program,

Pendidikan Kesehatan

Model Stake

\section{PENDAHULUAN}

Kesehatan sebagai hak asasi manusia dan salah satu unsur kesejahteraan yang menjadi tanggung jawab setiap orang, keluarga dan masyarakat serta didukung oleh pemerintah. Undang-undang RI Nomor 36 Tahun 2009 tentang Kesehatan mengamanatkan Pembangunan Kesehatan ditujukan untuk meningkatkan kesadaran, kemauan dan kemampuan hidup sehat bagi setiap orang agar terwujud derajat kesehatan masyarakat yang setinggitingginya, sebagai investasi bagi pembangunan sumber daya manusia yang produktif secara sosial dan ekonomis. Untuk mewujudkan masyarakat yang sadar akan kesehatan dapat ditempuh melalui pendidikan kesehatan.

Pendidikan kesehatan merupakan suatu cara penunjang program-program kesehatan yang dapat menghasilkan perubahan dan peningkatan pengetahuan dalam waktu yang pendek. Konsep pendidikan kesehatan merupakan proses belajar pada individu, kelompok atau masyarakat dari tidak tahu tentang nilai-nilai kesehatan menjadi tahu, dari tidak mampu mengatasi masalah kesehatan menjadi mampu (Notoatmodjo, 2007).

Pendidikan kesehatan dapat berperan untuk merubah perilaku individu, kelompok dan masyarakat sesuai dengan nilai-nilai kesehatan. Perubahan perilaku yang diharapakan adalah dapat memelihara dan meningkatkan kesehatan, mencegah risiko terjadinya sakit, melindungi diri dari ancaman penyakit, serta berpartisipasi aktif dalam gerakan kesehatan masyarakat sehingga perubahan perilaku merupakan hasil dari pendidikan kesehatan (Notoatmodjo, 2007). Pendidikan kesehatan harus merata ke seluruh pelosok negeri, baik di daerah perkotaan maupun daerah pedesaan.

Pulau Bali adalah salah satu bagian dari Indonesia. Bali merupakan daerah yang memiliki keragaman potensi wisata meliputi potensi wisata alam dan potensi wisata budaya disertai dengan keramahtamahan masyarakatnya menjadikan Bali sebagai daerah tujuan wisata utama di Indonesia. Arus kedatangan wisatawan baik dari dalam maupun luar negeri sangat lancar. Keberhasilan Bali dalam menarik wisatawan untuk berkunjung telah banyak memberi manfaat kepada masyarakat, melalui penciptaan lapangan kerja, mendorong ekspor hasil-hasil industri kerajinan serta sebagai sumber devisa daerah bahkan dalam beberapa dasa warsa sektor pariwisata telah mampu menjadi generator penggerak

\footnotetext{
* Corresponding author. 
(leading sector) perekonomian daerah Bali (Pitana, 1999:45). Kejenuhan terhadap bentuk wisata modern dan ingin kembali merasakan kehidupan di alam pedesaan serta berinteraksi dengan masyarakat dan aktifitas sosial budayanya menyebabkan berkembangnya pariwisata di daerah-daerah pedesaan yang dikemas dalam bentuk desa wisata.

Desa penglipuran merupakan salah satu desa wisata yang sangat terkenal dikalangan wisatawan baik lokal maupun manca Negara, karena disamping memiliki obyek wisata, kerukunan, kebersamaan adat yang kental juga didukung oleh perilaku masyarakat yang sehat dintaranya sekitar jalan utama desa tidak menemukan sampah yang beserakan yang mengotori Desa tersebut, terdapat banyak bak sampah yang disediakan untuk menampung sampah, cakupan imunisasi dasar mencapai 100\%, tidak ada gizi buruk, kendatipun MCK keadaannya kurang baik (Sang Made Agus Dwipayana, 2010) Dukungan masyarakat terhadap perilaku sehat tidak terlepas karena adanya program pendidikan kesehatan masyarakat dari Puskesmas pembantu kubu dan puskesmas induk Bangli Utara yang merupakan wilayah kerja desa wisata penglipuran. Pusat Kesehatan Masyarakat (Puskesmas) sebagai ujung tombak pelayanan kesehatan masyarakat merupakan sarana kesehatan yang penting dalam meningkatkan derajat kesehatan. Penelitian ini bertujuan untuk mengetahui evaluasi program pendidikan kesehatan meliputi relevansi, proses dan dampak pelaksanaan program apa adanya, kebenarannya dalam meningkatkan derajat kesehatan masyarakat yang dilaksanakan di desa wisata penglipuran. Fokus penelitian diarahkan pada evaluasi program pendidikan kesehatan dalam kaitannya meningkatkan derajat kesehatan masyarakat sehingga mendukung kedatangan wisatawan dunia.

\section{METODE PENELITIAN}

Jenis penelitian ini adalah penelitian kualitatif. Menurut meleong dalam Herdiansyah, penelitian kualitatif adalah suatu penelitian ilmiah yang bertujuan untuk memahami suatu fenomena dalam konteks sosial secara alamiah dengan mengedepankan proses interaksi komunikasi yang mendalam antara peneliti dengan fenomena yang diteliti (Herdiansyah, 2010). Model Penelitian kualitatif yang dilaksanakan berupa penelitian evaluasi menggunakan stake,s countenance model yang dikembangkan oleh Robert E. Stake. Evaluasi model ini terdiri dari tiga tahap yaitu masukan (antecedents), proses (transactions) dan hasil (out comes) Setiap tahapan dibagi menjadi dua tahapan yaitu deskripsi dan keputusan/penilaian (judment).

Model stake ini berorientasi pada pengambilan keputusan (decision oriented) dan teknik pengambilan keputusan aktualitas pada setiap tahap evaluasi atau aspek dengan cara melakukan pengukuran pada setiap focus evaluasi (Sabarguna, 2005) Obyek penelitian ini adalah evaluasi program pendidikan kesehatan di desa wisata penglipuran sedangkan subyeknya sebagai sampel terdiri dari 12 tokoh masyarakat, 5 orang penerima pendidikan kesehatan serta 70 orang pengisi angket masyarakat penerima penkes di desa wisata penglipuran Kabupaten Bangli. Informan adalah orang yang dimanfaatkan untuk memberikan informasi tentang situasi dan kondisi latar penelitian (Nawawi Hadari, 1992). Cara pengambilan sampel dengan Purposive sampling adalah tehnik pengambilan sampel dengan pertimbangan tertentu dengan ciri seperti bola salju, sesuai dengan kebutuhan dan dipilih sampai jenuh(Sugiyono, 2010) Alasan mengambil purposive sampling karena sampelnya dipilih berdasarkan kebutuhan dan tidak semua populai mendapat kesempatan menjadi sampel (Arikunto, 2010) Instrumen yang digunakan dalam penelitian ini adalah wawancara, angket, observasi dan dokumentasi.

\section{ANALISIS DAN PEMBAHASAN}

Relevansi pelaksanaan Pendidikan kesehatan dengan kebutuhan masyarakat Desa wisata penglipuran merupakan salah satu dari tiga lingkungan yang ada ( Lingkungan kubu,penglipuran dan tegal suci) dikelurahan kubu, yang pada tahun 2016 memiliki jumlah penduduk 991 orang terdiri dari laki 497 orang dan perempuan 494 orang dengan jumlah $235 \mathrm{KK}$, jumlah ibu hamil satu orang dan jumlah Balita 72 orang dipimpin oleh seorang kepala lingkungan dan kepala desa wisata.(Wibowo, 2016) Penglipuran mempunyai arti sebagai tempat hiburan (Penglipur) bagi raja-raja di Bangli, dan sampai saat ini Penglipuran merupakan salah satu obyek wisata di Kabupaten Bangli (Supat, 2016). Data kunjungan pasien penglipuran ke puskesmas pembantu tahun 2016 sebanyak 36 orang dengan kiteria penyakit Ispa 12 orang, Rematik 4 orang, ambien 1 orang, infeksi kulit 8 orang, Diare 1 orang, ISK 1 orang, caries 1 orang, chepalgia 2 orang, dan hipertensi 1 orang. Data kesehatan tahun 2016 di desa wisata penglipuran diantaranya kasus keracunan makanan pada anak sekolah 10 orang, tidak ada gizi buruk, kasus HIV/AIDS 1orang, seluruh masyarakat menggunakan air bersih dari PDAM atau air bersih dari mata air yang dikelola oleh desa adat, cakupan imunisasi tahun 2015 sebanyak 63,6 \%, dan tahun 2016 sebanyak 63,6 $\%$ per September, angka kelahiran tahun 2015 sebanyak 8 orang dan tahun 2016 sebanyak 8 orang per 
September, angka kematian tahun 2015 sebanyak 6 orang dan tahun 2016 sebanyak 2 orang, Jumlah pemakai KB tahun 2015 sebanyak 133 orang dan tahun 2016 sebanyak 138 orang, jumlah perawat dan bidan di desa penglipuran 4 orang. Tahun 2015 kondisi puskesmas pembantu rusak berat tetapi Oktober tahun 2016 sudah menjadi baik (Wayan Winasih, 2016).

Berdasarkan observasi tumbuhan terlihat selalu hijau, disekitar jalan utama desa tidak menemukan sampah yang beserakan yang mengotori desa tersebut dan terdapat banyak bak sampah yang disediakan untuk menampung sampah. Di saat mulai memasuki areal desa terdapat areal pertamanan dan juga balai pertemuan, sedangkan kendaraan bermotor tanpa kecuali tidak diperbolehkan memasuki areal perumahan. Memasuki areal para tamu disuguhi pemandangan unik dengan sajian perumahan yang di tata rapi yang mana dengan pintu masuk, bentuk bangunan, dan bahan dasar pembuatan sama dan hampir semuanya masih tradisional. Berdasarkan data tersebut dapat disimpulkan bahwa keberadaan data kesehatan tersebut sangat relevan dengan visi misi yang dicanangkan oleh puskesmas Bangli utara, apa lagi penglipuran adalah desa wisata dunia. Desa wisata adalah suatu bentuk antara atraksi, akomodasi dan fasilitas pendukung yang disajikan dalam suatu struktur kehidupan masyarakat yang menyatu dengan tata cara dan tradisi yang berlaku (Nuryanti, 1993) Keberhasilan pembangunan kesehatan tersebut merupakan salah satu keberhasilan program pendidikan kesehatan.

Menurut Notoatmodjo Pendidikan kesehatan adalah suatu upaya atau kegiatan untuk menciptakan perilaku masyarakat yang kondusif untuk kesehatan artinya, pendidikan kesehatan berupaya agar masyarakat menyadari atau mengetahui bagaimana cara memelihara kesehatan mereka, bagaimana menghindari atau mencegah hal - hal yang merugikan kesehatan mereka dan kesehatan orang lain, kemana seharusnya mencari pengobatan jika sakit, dan sebagainya (Notoatmodjo, 2007). Proses pelaksanan pendidikan kesehatan di desa wisata penglipuran dilihat dari dua sisi yaitu efektif dan efisiensi. a). Efektif menggambarkan tingkat pencapaian target dan prosedur pelaksanaan. Dalam mencapai target program pendidikan kesehatan maka program promosi kesehatan bekerja sama dengan pemberdayaan masysrakat dan program lainnya.

Proses diawali dengan mini loka karya penilaian program awal januari 2016 yang di targetkan dalam program promosi kesehatan di wilayah puskesmas bangli utara. Oleh karena itu target promosi kesehatan meliputi kelas balita 8 kali, penyuluhan kanker serviks 1x, Demam berdarah 1x, keracunan makanan 1x,komplementer 1x,gizi 1x, kesehatan lingkungan $1 \mathrm{x}$ dan penyuluhan survey mawas diri 40 orang dan pemberdayaan masyarakatnya adalah senam lansia 8 kali, pembinaan Kader Posyandu 8 x. Mawas diri adalah metode penyuluhan dengan melihat langsung perilaku masyarakat hidup sehat dan memberi kuis mengukur pengetahuan kesehatannya dan bila tidak mengerti langsung memberikan pemecahannya. Materi mawas diri antara lain KIA-KB, gizi keluarga, HIV/ AIDS dan diare. Penerima manfaat pendidikan kesehatan secara berkelompok pada saat penyuluhan kesehatan bersamaan posyandu adalah kelompok balita berjumlah 70 orang, kelompok lansia 12 orang, ibu hamil 6 orang , kader PKK 20 orang, STT sebanyak 35 orang. Dari data tersebut dapat disimpulkan target yang dicapai cukup efektip dari jumlah penduduk desa wisata sebanyak 991 orang dengan jumlah $235 \mathrm{KK}$.

Prosedur melaksanaan pendidikan kesehatan yaitu puskesmas induk bersurat (dengan dilampiri jadwal kegiatan yang sudah disepakati) kepada kelurahan dan tembusannya kepada pustu. Tupoksi dari pada Puskesmas pembantu adalah tupoksi yang dibuat oleh puskesmas induk dimana fungsi puskesmas pembantu diantaranya adalah mendukung pelaksanaan kegiatan posyandu, imunisasi, KIA, penyuluhan kesehatan, surveilans, pemberdayaan masyarakat dan mendukung pelayanan promotif dan preventif. Menurut Kepmenkes RI No. 128/Menkes/SK/II/2004 puskesmas merupakan Unit Pelayanan Teknis Dinas kesehatan kabupaten/kota yang bertanggung jawab menyelenggarakan pembangunan kesehatan di suatu wilayah kerja (Kemenkes RI, 2004) Prosedurnya pada perorangan adalah pada saat pasien berobat ,sebelum pengobatan di ruang tunggu ditempelkan leaflet, bander tentang kesehatan dan diakhir prosedur pengobatan pasien diberi edukasi tentang penyakit, cara perawatan dan pencegahannya.

Penyuluhan secara kelompok atau massa dilakukan bersama sesuai dengan kegiatan puskesmas induk. Dari data tersebut dapat disimpulkan prosedur pelaksanaan pendidikan kesehatan ada kerjasama dan koordinasi yang cukup efektip dengan kelurahan dimana setiap kegiatan yang dilaksanakan puskesmas untuk masyarakat penglipuran. Kesimpulan terakhir dari pembahasan efektifitas pelaksanaan pendidikan kesehatan diperoleh nilai kategori masih efektip, walau masih perlu peningkatan setiap kegiatannya. b).Efisiensi memperlihatkan perbandingan antara out put dengan input yang bisa dilakukan secara kelompok dan individual. Proses pelaksanaan pendidikan kesehatan pada kelompok dari sisi input telah dilakukan lokakarya penilaian program, kemudian membagi habis tugas yang dibuat dalam bentuk Tupoksi, kemudian dari sisi out put dilakukan evaluasi dimana evaluasi dilakukan $4 \mathrm{x}$ dalam setahun dan diakhir tahun juga dilakukan evaluasi dalam bentuk loka karya mini yang hasilnya tigkat keberhasilan program yang dilaksanakan. Dalam melaksanakan program selalu mengadakan kerja sama dan koordinasi 
diantaranya koordinasi antara puskesmas, kelurahan,dan desa wisata penglipuran, koordinasi dengan promkes kendatipun materi penkes itu diberikan oleh seksi pelayanan yang membidanginya sehingga tidak terjadi tumpang tindih dalam pelaksanaannya, dan dilaksanakan bersamaan dengan kegiatan Posyandu. Proses pelaksanaan pendidikan kesehatan secara individual dilaksanakan di puskesmas pembantu kubu dengan cara pada saat pasien berobat ,sebelum pengobatan di ruang tunggu ditempelkan leaflet, bander tentang kesehatan dan diakhir pelayanan pengobatan pasien diberi edukasi tentang penyakit, cara perawatan dan pencegahannya (Wayan Winasih, 2016).

Dampak yaitu pengaruh dari program penelitian ini adalah pengaruh program pendidikan kesehatan terhadap masyarakat desa wisata penglipuran bangli yang di koordinir oleh seksi pelayanan promosi kesehatan atau promkes. Dalam hal ini dampak adalah efek suatu program baik efek primer atau sekunder, berikut pembahasanya.

Efek primer adalah peningkatan pengetahuan dan implementasi PHBS. Adapun efek yang terjadi pada masyarakat diantaranya akseptor KB meningkat dari 133 orang tahun 2015 menjadi 138 orang tahun 2016, penurunan angka kematian dari 6 orang tahun 2015 menjadi 2 orang tahun 2016, cakupan imunisasi bertahan 63,6 \%. Efek secunder adalah kejadian kasus keracunan makanan tidak ada, meningkatnya perilaku hidup bersih dengan tetap pemakaian air bersih $100 \%$, seluruh masyarakat memakai jamban bersih, tempat sampah yang bersih semakin banyak,tidak ditemukannya kasus demam berdarah tetap tidak adanya gizi buruk, Ibu hamil 1 orang, tidak ditemukannya ada sampah. Untuk mengetahui dampak atau keluaran dari pendiddikan kesehatan dilakukan kesimpulan dari 5 anggota penerima pendidikan kesehatan yang diwawancarai dengan hasil sebagai berikut:

Seorang ibu berusia 28 tahun sedang hamil 8 bulan sudah mengikuti senam hamil $4 \mathrm{x}$ menyatakan bahwa proses pendidikan senam hamil yang diikuti sangat baik, karena bimbingan dilakukan secara langsung, pada awal belajar dikasih pretes tentang kehamilan setelah selesai juga diberikan tes kehamilan dilakukan pada ruangan yang nyaman, disiapkan bantal dan karpet, sudah dibuatkan jadwal setiap hari jumat. Pada saat pemeriksaan kehamilan ke puskesmas pembantu diberikan penkes secara individual dengan cara setelah pemeriksaan diberikan obat dan dijelaskan cara minum obat serta perawatan persiapan akan melahirkan..

Seorang kader pkk usia 36 tahun juga pengusaha loloh cemcem menyatakan bahwa pernah mengikuti pendidikan kesehatan tentang manfaat herbal dan kanker servik, saat itu penkes dilakukan dengan slide berisi gambar , diberikan leaflet, dan diberi waktu tanya jawab, informasi diadakan penkes diperoleh dari kepala lingkungan, penkes lain yang pernah diikuti diantaranya Diare, perilaku hidup bersih, lingkungan bersih, KB, Peningkatan gizi, DHF.

Seorang ibu usia 33 tahun memiliki anak kelas 2 SD, menyatakan program pendidikan kesehatan sudah baik terutama demam berdarah dan keracunan makanan. Pada saat penkes dilakukan dengan slide berisi gambar, diberikan leaflet, dan diberi waktu tanya jawab, informasi diadakan penkes diperoleh dari kepala lingkungan.

Seorang ibu usia 40 tahun memiliki anak umur 3 tahun yang aktif di kelas balita menyatakan program pendidikan kesehatan sudah baik terutama kelas balita. Penyuluhan secara individual pernah diperoleh saat methode survey mawas diri, dengan materi diare, demam berdarah dan perilaku hidup bersih. Seorang bapak usia 55 tahun mengalami rematik, menyatakan program pendidikan kesehatan secara individual sudah baik karena setiap berobat ke puskesmas pembantu kubu setelah pemeriksaan diberikan obat dan dijelaskan cara minum obat dan efek sampingnya. Dalam rangka keabsahan data digunakanlah teknik triangulasi yaitu dengan hasil angket tentang pengetahuan pendidikan kesehatan pada masyarakat desa penglipuran sebanyak 70 orang dengan hasil seperti pada Tabel 1.

Tabel 1. Tingkat Pengetahuan Pendidikan Kesehatan Masysrakat Penglipuran

\begin{tabular}{cccc} 
No & Tingkat pengetahuan Pendidikan & \multicolumn{2}{c}{ JUMLAH } \\
Kesehatan & & & \\
\cline { 3 - 4 } & & $\mathrm{F}$ & $\%$ \\
1 & Sangat baik & 45 & 64 \\
2 & Baik & 24 & 34 \\
3 & Kurang & 1 & 2 \\
& JUMLAH & 70 & 100 \\
\hline
\end{tabular}


Berdasarkan tabel 1 terdapat tingkat pengetahuan pendidikan kesehatan mayoritas sangat baik $64 \%$, baik $34 \%$ orang dan kurang $2 \%$. Dengan data tersebut berarti ada kesesuaian informasi yang dikumpulkan dari 12 tokoh masyarakat yang menyatakan ada relevansi yang cukup terhadap kebutuhan pendidikan kesehatan, masih efektip dan efisiensinya pelaksanaan program pendidikan kesehatan dan dampak yang positip terhadap perilaku kesehatan masyarakat penglipuran.

\section{KESIMPULAN}

Penglipuran merupakan salah satu desa wisata di bali yang masyarakatnya masih memegang teguh adat, tradisi dan budaya jaman terdahulu dengan konsep trihita karana diwariskan kepada generasi penerusnya, sehingga tampak bangunan yang asri, menarik dan pemikat wisata dunia. Program pendidikan kesehatan di desa wisata penglipuran cukup relevan dalam rangka merubah perilaku masyarakat sebanyak 991 orang bisa hidup lebih sehat, pencegahan penyakit dan mencari pertolongan lebih cepat bila keadaan sakit. Pelaksanaan program pendidikan kesehatan didesa wisata penglipuran telah dilakukan cukup efektif dan efisiensi dengan prosedur koordinasi dan kerja sama yang kuat antara puskesmas, kelurahan dan masyarakat penglipuran sehingga berdampak positip terhadap desa wisata penglipuran.

\section{DAFTAR PUSTAKA}

Arikunto. (2010). Prosedur Penelitian Suatu Pendekatan Praktek.

Herdiansyah, H. (2010). Metodologi penelitian kualitatif untuk ilmu-ilmu social.

Kemenkes RI. (2004). Peraturan Menkes RI Nomor 128/Meskes/SK/II/2004 tentang kebijakan dasar Puskesmas. Jakarta.

Nawawi Hadari. (1992). Instrumen penelitian bidang social. Yogyakarta: Gajah Mada University Press.

Notoatmodjo, S. (2007). Ilmu Kesehatan Masyarakat ; Prinsip-prinsip Dasar. Jakarta: Rineka Cipta.

Nuryanti, W. (1993). Concept, Perspective and Challenges, makalah bagian dari Laporan Konferensi Internasional mengenai Pariwisata Budaya. Jogyakarta: Gadjah Mada University Press.

Pitana, I G., 1999, Pelangi Pariwisata Bali,Denpasar, Bali Post.

Sabarguna, S. B. (2005). Analisis data kualitatif. Jakarta: UI Press.

Sang Made Agus Dwipayana. (2010). Profil Desa Kubu. Bangli: 20Kelurahan\%20Kubu.html.

Sugiyono. (2010). Metode Penelitian Pendidikan pendekatan kuantitatif kualitatif dan R\&D. Bandung.

Supat, W. (2016). Wawancara pribadi dengan kepala desa wisata.

Wayan Winasih. (2016). Wawancara pribadi dengan kepala puskesmas pembantu kelurahan kubu Bangli.

Wibowo, A. (2016). Wawancara pribadi dengan kepala lurah kubu Bangli. Bangli. 